\title{
JOVENS OLHARES SOBRE A ESCOLA DO ENSINO MÉDIO
}

\author{
Geraldo Leāo* \\ Juarez TARCísio Dayrell ${ }^{* *}$ \\ Juliana Batista dos Reis ${ }^{* * *}$
}

\begin{abstract}
RESUMO: Este artigo discute os resultados de uma pesquisa realizada com estudantes do Pará sobre as relações entre projetos de vida de jovens e as escolas públicas de ensino médio. Os dados foram coletados em 2009, por meio de doze Grupos de Diálogos com 245 jovens, organizados em duas cidades do interior do estado (Moju e Santarém) e na capital. A partir dos depoimentos dos jovens, foi possível identificar algumas contribuiçōes das escolas à realização de suas demandas e expectativas, mas também muitas lacunas e impasses. $\mathrm{O}$ texto parte de uma discussão geral sobre o contexto do ensino médio no país e a relação com a juventude para situar a realidade específica das escolas paraenses segundo o olhar dos jovens pesquisados, compreendendo assim as distâncias e aproximaçôes entre as expectativas juvenis e as experiências oferecidas por suas escolas.
\end{abstract}

Palavras-chave: Educação. Ensino médio. Juventude.

\section{FRESH LOOKS ON HIGH SCHOOL}

ABSTRACT: This paper discusses the results of a research carried out with students from the State of Pará on the relations between the life projects of youth and public high schools. Data were collected in

* Doutor em Educação e professor adjunto da Faculdade de Educação e do Programa de PósGraduação em Educação da Universidade Federal de Minas Gerais (UFMG). E-mail: gleao2001@yahoo.com.br

** Doutor em Educação e professor associado da Faculdade de Educação e do Programa de Pós-Graduação em Educação da UfMG. E-mail: juareztd@uol.com.br

*** Doutoranda em Educação pelo Programa de Pós-Graduação em Educação da UFMG e pesquisadora do Observatório da Juventude da mesma Universidade. E-mail: jubtr@yahoo.com.br 
2009 through twelve Dialogue Groups with 245 students from two hinterlands cities (Mojú and Santarém) and the Capital. These declarations allowed us to identify some of the schools' contributions to the concretization of their demands and expectations, as well as many gaps and dead ends. The text begins with a general discussion on the Brazilian high school context and the relationship with youth. It then situates the specific reality of schools in Pará, according to the youth's point of view, and tries to comprehend the distances and approximations between youth expectations and the experiences offered by their school.

Key words: Education. High school. Youth.

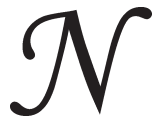

este artigo, buscamos discutir a realidade do ensino médio na ótica dos jovens alunos, problematizando os sentidos que atribuem à vivência escolar. Trata-se de um dos resultados da pesquisa Ensino Médio em Diálogo, realizada no estado do Pará, em 2009, no âmbito do projeto Diálogos com o Ensino Médio, ${ }^{1}$ que teve como objetivos apreender e analisar a situação do ensino médio nesse estado, na ótica dos jovens alunos, buscando analisar os sentidos atribuídos e as expectativas dos jovens alunos em relação a esse nível de ensino. No contexto desses objetivos mais gerais, optamos em centrar a investigação em torno da relação que os jovens estudantes estabelecem entre os processos educativos e seus projetos de vida.

Buscamos ainda discutir especificamente a visão dos jovens alunos sobre a sua vivência escolar, evidenciando suas demandas e necessidades em relação ao ensino médio. $\mathrm{O}$ texto parte de uma discussão geral sobre este nível de ensino no país, evidenciando a importância de se levar em conta nas análises o aluno como jovem. Em seguida, partimos para uma descrição dos jovens alunos pesquisados, finalizando com os resultados da pesquisa desenvolvida.

\section{Os desafios do ensino médio e a juventude}

Os dilemas enfrentados pela educação nos últimos anos não se restringem ao ensino médio, tampouco ao contexto brasileiro. Tais dilemas têm sido definidos como uma crise de legitimidade da escola (Krawczyk, 2009), como um reflexo das profundas mutações que vêm 
afetando as sociedades ocidentais e que interferem nas instituições e processos socializadores (Dayrell, 2007), como um momento de mutação na educação (Canário, 2005) ou ainda como uma "etapa não apenas de estancamento, mas de regressão no campo educativo" (Gadotti, 1992, p. 75). Seja qual for a tese utilizada para caracterizar o momento vivido atualmente pela instituição escolar e pela educação, o que se destaca é a distância entre o que a sociedade espera da escola e o que a escola tem sido capaz de oferecer.

A situação parece se acirrar especificamente com o ensino médio, que enfrenta desafios consideráveis. Um deles, que nos interessa mais de perto, refere-se à expansão das matrículas ocorrida a partir dos anos de $1990^{2}$ e a ampliação da obrigatoriedade e gratuidade desse nível de ensino, ${ }^{3}$ o que tem gerado uma mudança significativa do perfil dos jovens alunos que chegam a ele. As escolas públicas de ensino médio no Brasil até então eram restritas a jovens das camadas altas e médias da sociedade, os "herdeiros", segundo Bourdieu (2003), com certa homogeneidade de habilidades, conhecimentos e de projetos de futuro. Elas passam então a receber um contingente de alunos cada vez mais heterogêneo, marcado pelo contexto de uma sociedade desigual, com altos índices de pobreza e violência que delimitam os horizontes possíveis de ação dos jovens na sua relação com essa instituição. Os conflitos e contradições de uma estrutura social excludente se tornam mais explícitos em seu interior, interferindo nas suas trajetórias escolares e sentidos atribuídos a ela. Novos desafios se apresentam então à escola e seus profissionais (Sposito, 2005).

Tal expansão ainda não respondeu às necessidades de universalização desse nível de ensino. Segundo dados do Instituto de Pesquisa Econômica Aplicada (IPEA) (Castro et al., 2009), aproximadamente $82 \%$ dos jovens de 15 a 17 estudavam em 2007, mas apenas 48\% deles cursavam o ensino médio, o que indica uma enorme defasagem série/idade. Mais sério ainda é o fato de que 32,7\% dos jovens de 15 a 19 anos não estavam estudando em 2007, evidenciando o desafio de democratização do acesso aos anos finais da educação básica.

Outro desafio a ser enfrentado se refere à identidade do ensino médio. Há uma permanente tensão entre formação geral e/ou profissional, ensino propedêutico e/ou técnico, que diz respeito ao papel da escola média como etapa final do ensino básico e sua relação com o 
mercado de trabalho, com o ensino superior e com a formação pensada em termos mais amplos, relacionada às noçôes de autonomia e cidadania. Acresce-se a necessidade de docentes com formação adequada ao desenvolvimento do trabalho com jovens, de novas tecnologias educacionais no contexto escolar e de rever as relações professor/aluno e jovem/adulto no contexto escolar, entre outros desafios (Krawczyk, 2009). Acrescentamos ainda a necessidade de desvendar o papel e o sentido atribuídos pelos jovens à escola, o que aponta para a discussão necessária sobre as possíveis relações que os jovens estabelecem entre os seus projetos de vida e a experiência escolar.

Nesse sentido, propomos o deslocamento da análise da instituição escolar para os sujeitos jovens, centrando neles o eixo da investigação. Partimos da constatação de que existe uma nova condição juvenil no Brasil, resultado das mutações nos processos mais amplos de socialização (Dayrell, 2007). O jovem que chega às escolas públicas, na sua diversidade, apresenta características, práticas sociais e um universo simbólico muito diferente das geraçōes anteriores. ${ }^{4}$

Entre as dimensões dessa nova condição juvenil, pode ser apontada a origem social, marcada pela pobreza, fazendo com que a escola e o trabalho sejam realidades que se superpõem ou sofrem ênfases diversas. Outra dimensão pontuada são as culturas juvenis, evidenciando que o mundo da cultura aparece como um espaço privilegiado de práticas, representações, símbolos e rituais, no qual os jovens buscam demarcar uma identidade juvenil. Ou mesmo a sociabilidade, apontando a centralidade dessa dimensão que se desenvolve entre os grupos de pares, preferencialmente nos espaços e tempos do lazer e da diversão, mas também presente nos espaços institucionais como na escola ou mesmo no trabalho. Essas diferentes dimensões da condição juvenil se configuram a partir do espaço onde são construídas, que passa a ter sentidos próprios, transformando-se em lugar, o espaço do fluir da vida, do vivido, sendo o suporte e a mediação das relaçôes sociais, investido de sentidos próprios, além de ser a ancoragem da memória, tanto individual quanto coletiva.

É através dessas dimensões, entre outras, que os jovens vão se construindo como tais, com uma identidade marcada pela diversidade nas suas condições sociais, culturais (etnias, identidades religiosas, valores etc.), de gênero e até mesmo geográficas, entre outros aspectos. A juventude se constitui como um momento delicado de escolhas, de 
definições, no qual o jovem tende a se defrontar com perguntas como: "Para onde vou?", "Qual rumo devo dar à minha vida?", questôes estas cruciais para o jovem e diante das quais a escola teria de contribuir de alguma forma, no mínimo na sua problematização.

Foi nessa perspectiva que a pesquisa Diálogos com o Ensino Médio foi desenvolvida, tendo em vista a compreensão da realidade do ensino médio e seus desafios, especialmente no que se refere à lacuna existente na compreensão do aluno desse nível de ensino como jovem. Nesse sentido, a escolha metodológica de eleger os jovens como sujeitos da investigação fundamenta-se em um pressuposto de pesquisa. Parte-se da ideia de que os jovens estudantes são interlocutores válidos e privilegiados para a compreensão do ensino médio.

A escolha dessa perspectiva implicou uma mudança no eixo da análise, passando das instituiçôes educativas para os sujeitos jovens, em que a escola passa a ser problematizada a partir da ótica destes últimos, buscando compreender as suas demandas e necessidades em relação à instituição escolar. Ao centrar a investigação em torno da realidade escolar que vivenciavam, buscou-se apreender dessa forma os sentidos que os jovens atribuem à escola e ao ensino médio. Quais as visôes que possuem sobre a sua vivência escolar? Quais os significados que atribuem à escola? Quais os desafios que apontam? Será que correspondem às questôes evidenciadas acima pelos estudiosos do ensino médio? São indagações que buscaremos problematizar.

\section{A pesquisa e o contexto}

Como já afirmamos, a pesquisa foi desenvolvida no estado do Pará em 2009. A seleção do estado em que seria realizada a pesquisa deu-se a partir da demanda do MEC, a partir dos resultados do Índice de Desenvolvimento da Educação Básica (IDEB) de 2007. Nesse ano, o Pará foi a unidade da Federação que apresentou o menor IDEB entre os estados brasileiros. Dessa forma, buscou-se compreender as percepções que os atores diretamente relacionados à escola, especificamente os jovens, apresentavam sobre ela, tendo como referência a realidade educacional desse estado.

A definição dos procedimentos de campo está intrinsecamente relacionada ao problema de pesquisa em questão. Se, em um primeiro 
momento, foi necessário avistar um quadro geral dos contextos social, econômico e cultural em que a população jovem do Pará está inserida, posteriormente foi imprescindível escutar os sujeitos de pesquisa sobre suas vivências e expectativas. As cidades e escolas e a amostra da pesquisa foram selecionadas a partir de bases de dados secundárias do IBGE e do Instituto Nacional de Estudos e Pesquisas Educacionais (INEP). ${ }^{5}$ Para alcançar a voz dos jovens, desenvolvemos doze Grupos de Diálogos (GD) com 245 estudantes do ensino médio de três cidades do estado: Moju, Santarém e a capital Belém, com uma média de três horas cada encontro.

A metodologia dos GD parte do pressuposto de que os sujeitos, colocados em situação de interação e diálogo, estimulados a refletirem sobre um tema proposto, não apenas manifestam suas opiniōes, mas partilham, aprofundam e modificam suas percepções, representações e pontos de vista. Nos doze GD realizados, cada um deles com a duração de quatro horas, os jovens foram convidados a falar sobre seus projetos de vida e as contribuiçõos e não contribuições do ensino médio que eles frequentavam para a realização. ${ }^{6}$

\section{Jovens sujeitos de pesquisa}

Para traçar um perfil dos jovens sujeitos de pesquisa, ou seja, os participantes dos doze GD, foram utilizados os dados colhidos em um questionário que foi respondido individualmente pelos jovens, antes do início das atividades de cada grupo. Com esses dados, procuramos traçar um breve perfil através de alguns dados socioeconômicos dos jovens pesquisados, que acabam por delinear um contorno geral e caracterizações desse grupo. O total da amostra foi de 245 respondentes, sendo que o número de jovens por cidade de moradia foi de 126 de Belém, 88 de Santarém e 31 da cidade de Moju.

Levando-se em conta a faixa etária dos participantes, todos eles matriculados no terceiro ano do ensino médio, 95 respondentes $(39 \%)$ tinham entre 16 e 18 anos, 85 (35\%) situavam-se entre 19 e 21 anos e $51(21 \%)$ tinham acima dos 22 anos de idade, sendo que 14 (5\%) não responderam. Isso indica uma defasagem idade/série para mais de $60 \%$ dos jovens. Sobre o estado civil, a grande maioria era de solteiros (90\%), como era de se esperar, sendo uma pequena minoria de casados 
ou amasiados (7\%). Entretanto, quando perguntados se tinham filhos, $16 \%$ responderam positivamente, indicando que havia uma parcela de pais e mães solteiros.

Outro dado significativo refere-se ao trabalho. Dos jovens pesquisados, 38,4\% (94) estavam trabalhando no período da pesquisa, enquanto $61,6 \%$ (151) estavam desempregados ou nunca trabalharam. Assim, para uma parcela significativa deles, a condição juvenil só é vivenciada porque trabalham, garantindo o mínimo de recursos para o lazer, o namoro ou o consumo. Para muitos, a iniciação ao trabalho ocorreu ainda na adolescência, por meio dos mais variados "biscates", caracterizando uma situação de instabilidade que tende a persistir ao longo da juventude. Mas isso não significa, necessariamente, o abandono da escola, apesar de influenciar no seu percurso escolar. Os dados mostram que até os 18 anos praticamente $20 \%$ dos jovens conciliavam escola e trabalho, proporção que vai diminuindo com o avanço da idade. Em torno de 35\% dos jovens contribuíam de alguma forma para o sustento da família.

Sobre a trajetória escolar, podemos constatar que boa parte dos jovens apresenta um percurso irregular. Levando em conta a faixa etária, podemos constatar a existência de $56 \%$ dos jovens em uma faixa acima daquela que seria esperada (15 a 17 anos), revelando uma defasagem série/idade considerável. Tal defasagem reflete de alguma forma a realidade brasileira, como já comentamos anteriormente. Buscando problematizar tais dados, as informações sobre a reprovação nos mostram que $43,7 \%$ dos jovens já haviam sido reprovados pelo menos uma vez. Isso indica uma experiência escolar marcada por insucessos, o que certamente influencia no envolvimento do jovem com a própria escola. Esses dados são reforçados pelo número significativo de quem já interrompeu a vida escolar (27,3\%).

Ainda sobre a trajetória escolar dos jovens, outro dado importante refere-se à escolaridade dos pais. Temos que 77,6\% dos pais não chegaram a completar o ensino médio, índice que cai para $64,1 \%$ no caso das mães. Assim, a grande maioria dos jovens pesquisados apresentava uma escolaridade maior do que a de seus pais, reflexo da expansão do ensino médio no Pará e no Brasil, conforme vimos anteriormente. Ou seja, encontram-se inseridos em uma família com pouca tradição escolar, o que interfere nas suas trajetórias. 
Os dados apresentados através desta amostra da pesquisa nos oferecem representações sobre os concluintes do ensino médio no estado do Pará. O instrumento da coleta de dados por questionários complementa um olhar sobre a condição juvenil e se fundamenta na perspectiva de compreender atores centrais na escola de ensino médio. Aqui esboçamos um perfil que precisa ser lido em complementaridade com a produção qualitativa dos Grupos de Diálogo.

As escolas nas perspectivas dos jovens

Convidados a falar sobre a sua escola, de uma maneira geral, os jovens tendiam a atribuir a ela uma grande importância. Com diferentes cores e pesos, a escola pública se apresentava como uma instituição central, mesmo reconhecendo os seus limites e lacunas. Alguns depositavam nela, ao menos no plano do discurso, um alto valor: "A escola é o alicerce do meu futuro, porque se a gente não passar por ela, a gente não vai conseguir o que a gente quer lá na frente” (GD 5). Outros jovens demonstravam um distanciamento crítico maior em relação às suas condições de funcionamento: "Através da escola é que a gente tem esse empurrão para ir para frente, mesmo a escola estando tão 'avacalhada' ela contribui. De uma forma 'aperreada' a escola ainda contribui” (GD 1). Dependendo do contexto e da trajetória social de cada jovem, nos depoimentos transpareciam tanto representações da escola como uma "promessa redentora", enfatizando tanto a importância da educação como fator de mobilidade social, quanto uma "adesão crítica” que, mesmo reconhecendo o seu papel, não deixava de indicar os seus limites.

A relação dos jovens com a escola é permeada por múltiplos sentidos e significados, por sentimentos positivos e negativos. Como espaço de encontro e sociabilidade, mas também do ponto de vista da sua função em termos de produção e transmissão de saberes e conhecimentos úteis à vida, à continuidade dos estudos e ao trabalho, ela é vista positivamente pelos jovens. Por outro lado, a ausência de políticas educacionais adequadas, os problemas de infraestrutura e pessoal, o funcionamento precário do turno da noite, entre outros problemas, produziam um sentimento de abandono que se expressava numa visão muito crítica sobre a escola (Dayrell et al., 2009). Conforme constatou 
Sposito (2005), os jovens brasileiros viveram a expansão recente das oportunidades educacionais em um contexto de crise social. Para a autora, a escola se constitui em uma referência para esta geração, fazendo parte de suas práticas e expectativas, "embora reconheçam os limites no impacto que a instituição escolar tem sobre suas vidas” (p. 123).

As questôes emergentes nos GD foram agrupadas em seis eixos: as condiçôes de funcionamento e infraestrutura, a gestão escolar, os professores, os estudantes, as aprendizagens e métodos de ensino e outras dimensões educativas. De uma maneira geral, podemos dizer que os dados encontram eco em outros estudos que indicam questôes semelhantes para as escolas do país (Corti \& Souza, 2009). Tais dimensões nomeadas pelos estudantes durante os vários GD demonstram um nível de consciência desses jovens em relação ao contexto em que vivem, seus limites e possibilidades, contrapondo-se a uma imagem distorcida deles como alienados ou passivos.

\section{As condições de funcionamento e a infraestrutura das escolas}

Um tema recorrente em todos os grupos dizia respeito às condições de funcionamento das escolas públicas. Em alguns casos, havia a constatação de que o quadro em relação à estrutura física e administrativa das escolas havia melhorado. Mas, em geral, os estudantes tenderam a relatar uma série de problemas ligados à falta de infraestrutura escolar, os quais vinculavam ao descaso do Estado.

Apesar das reformas educacionais empreendidas pelas políticas educacionais a partir dos anos de 1990, a escola pública ainda está longe de atingir um patamar adequado em relação às suas condições de funcionamento. Muitos depoimentos revelaram o abandono e a falta de investimentos no ensino médio público. Muitas falas retratavam as piores condições das suas escolas em relação à rede privada de ensino, especialmente no caso das noturnas e rurais. Diante da experiência cotidiana de estudar em uma "escola pobre para pobres", muitos jovens denunciavam as precárias condiçóes em que estudavam e manifestavam sua indignação diante desse quadro.

Um dos grandes motivos de reclamação dos alunos referia-se ao estado de conservação e higiene dos banheiros. Muitas vezes, eles chegavam à escola para estudar à noite sem que a limpeza fosse realizada. 
Outros relatavam que, quando o material era insuficiente, a escola reduzia o número de limpezas. Em alguns casos, os próprios alunos eram incentivados a fazer doações ou campanhas de arrecadação de produtos de limpeza. Em alguns relatos, registrou-se até mesmo a prática de trocar pontos da avaliação pela participação em campanhas de arrecadação de recursos: "Os alunos têm que ajudar com dinheiro para reformar a escola. Por exemplo: a escola faz um bingo e os alunos que comprarem ganham pontos. Mas as obras na escola não aparecem" (GD 5).

Outro aspecto dizia respeito à falta de climatização das salas de aula e de refrigeração da água consumida na escola. No estado do Pará, onde o clima quente e úmido prevalece, tal situação gera um grande desconforto para a realização das aulas.

Além do estado precário das escolas, chama a atenção o subaproveitamento da capacidade já instalada na rede estadual. A principal reclamação dos jovens referia-se a não utilização dos laboratórios, salas de informática e bibliotecas, particularmente no caso do ensino noturno. A não utilização dos laboratórios muitas vezes se dava pela falta de professores especializados e monitores para cuidar dos equipamentos e materiais. No caso das salas de informática, além da falta de pessoas para cuidar dos equipamentos, a morosidade na instalação da rede de comunicação dificultava o seu uso. Em geral, os professores não sabiam como utilizar a informática em suas disciplinas e não contavam com um suporte adequado na escola para desenvolverem projetos de ensino que utilizassem tais recursos.

Deve-se ressaltar que, durante a realização dos GD, manifestou-se uma grande diversidade de realidades entre os estabelecimentos da mesma rede de ensino, verificando-se casos como de escolas de Belém que, embora próximas umas das outras, viviam realidades muito discrepantes em termos das suas condiçōes de funcionamento e da sua estrutura física. Casos mais absurdos diziam respeito à diferença de funcionamento numa mesma escola, dependendo do turno estudado. De uma maneira geral, os cursos noturnos tendiam a ser prejudicados em termos de funcionamento de laboratórios e outros serviços, como limpeza e reprografia. Da mesma forma, também as escolas rurais costumavam funcionar em condições piores em relação às outras escolas, ainda que pertencentes ao mesmo sistema de ensino. 
O problema de infraestrutura escolar parece ser recorrente em muitos estados brasileiros. Em parte, isso se deve à resistência a ampliar os gastos com a educação e a opção por uma política de financiamento focalizada no ensino fundamental iniciada nos anos de 1990 e que perdurou até 2007 .

\section{Características ligadas à liderança e à gestão escolar}

Um aspecto muito citado nos GD dizia respeito ao papel dos diretores e dos coordenadores pedagógicos. Em geral, fazia-se referência à importância da presença desses profissionais na escola para manter a organização: "A diretora da escola é respeitada e a escola não é avacalhada" (GD 5). Além disso, a presença deles fazia diferença na motivação dos docentes e alunos. A proximidade dos gestores escolares, ouvindo e incentivando os alunos, quando ocorria, foi muito valorizada pelos jovens.

Uma das maiores reclamações dos entrevistados se referia exatamente à ausência da direção escolar, geralmente no turno noturno. Tal ausência acarretava uma falta de organização da escola nesse turno. Os coordenadores, além de cuidarem das demandas ligadas à organização pedagógica da escola, eram obrigados a resolver questóes de ordem administrativa. Ao sobrecarregar esses profissionais com diversas tarefas, a escola deixava de desenvolver outros projetos de ensino. Além disso, o sentimento de desorganização e a falta de controle tinham um impacto negativo no clima escolar, o que gerava um desejo de maior rigidez: "A escola precisa ser mais rígida!" (GD 1).

Ao mesmo tempo em que alguns desejavam uma melhor organização da escola, outros reclamavam da falta de diálogo e de flexibilidade do diretor em relação aos alunos. Nesse caso, embora o diretor estivesse presente, sua prática era vista como autoritária e pouco flexível com relação às normas escolares. A falta de escuta era uma das principais reclamações. Em um dos GD, os alunos exemplificaram com uma situação vivida por eles. $\mathrm{Na}$ escola citada, a sala de aula estava sem ventilador e mal iluminada, causando um grande desconforto, o que fez com que procurassem a secretaria e a direção. Como não foram ouvidos, eles decidiram não entrar para a sala de aula no dia seguinte, mesmo com a presença do professor. Somente assim o problema foi solucionado. 
Outro aspecto ressaltado dizia respeito à falta de adequação da escola em relação à realidade dos alunos e suas necessidades. Isso era evidente com relação ao horário de entrada na aula, que expressava um conflito muito comum nas escolas noturnas. Mas também se referia à dificuldade dos gestores em considerar a realidade vivida pelos alunos.

Em muitos casos, a discussão entre os jovens girou em torno da comparação entre escolas em que a direção era ausente ou pouco acessível para os estudantes e outros colégios em que havia uma relação mais próxima entre esses atores. Houve alguns casos em que os jovens que estudavam à noite se surpreendiam ao saber que os alunos dos turnos do dia tinham uma boa relação com a direção escolar. Muitas vezes, os alunos do noturno sequer conheciam esses profissionais. Isso expressa uma desigualdade no tratamento dos turnos que persiste na escola brasileira. Em muitos casos, a escola noturna tem um status secundário, traduzido na ausência de alguns profissionais específicos (bibliotecários, diretores, monitores de laboratórios) e na consequente falta de oferta de determinados serviços, como bibliotecas e reprografia.

Os impactos negativos com relação a esse aspecto não se referiam apenas aos problemas ligados à relação com direção escolar, mas também ao fato de que os alunos ficavam privados de informações sobre a escola (decisões e regras de funcionamento) ou sobre atividades das quais gostariam de participar (oficinas, seminários, atividades de lazer). Isso gerava um sentimento de exclusão, particularmente entre os estudantes do noturno: "A gente não é informado de nada" (GD 9). Perguntamo-nos em que medida podemos solicitar a adesão dos alunos, sua motivação para a vida escolar, sem cuidar da produção de um ambiente escolar em que os alunos se sintam valorizados.

De acordo com Soares et al. (2002), na perspectiva dos estudos sobre o efeito escola, ${ }^{7}$ a gestão administrativa e pedagógica escolar tem sido apontada como um fator decisivo em relação ao seu desempenho. A capacidade dos diretores em articular os sujeitos em torno de um projeto pedagógico comum, sua sensibilidade para interagir com as pessoas e conduzir adequadamente as relações entre os níveis administrativos e pedagógicos é um aspecto importante para compreender o desempenho da escola.

Os depoimentos dos jovens nos diferentes GD parecem apontar que a presença constante da direção e da coordenação, além de contribuir 
como suporte e orientação ao trabalho dos professores, possibilita que os alunos sejam informados, acompanhem as atividades realizadas pela escola e também possam apresentar suas demandas. Além disso, esses profissionais, quando estão presentes na escola, acabam transmitindo informações sobre eventos e atividades extraescolares que podem orientar os estudantes quanto às suas necessidades e projetos.

\section{O professor: um ator central}

Assim como em outras investigaçōes (Dayrell et al., 2009; Sposito \& Galvão, 2004), em todos os GD, os jovens ressaltaram a centralidade dos professores nas suas experiências escolares. Os estudantes tinham alguns docentes como referências e alimentavam boas expectativas quanto ao apoio e à orientação deles. Uma das imagens mais comuns era a representação do professor como um incentivador dos alunos, não apenas com relação aos estudos, mas também aos seus planos de vida de uma maneira geral. Geralmente, os depoimentos vinham acompanhados da imagem do professor como um orientador, aquele que dá conselhos e informações. Aqueles que apresentavam essas características eram vistos pelos jovens como comprometidos e interessados pelo seu trabalho e pelos alunos, o que se relacionava a várias posturas: "ser pontual"; "gostar do que faz", "se preocupar com o aluno", "tirar dúvidas", "ser acessível aos alunos", "dar espaço para o aluno fazer perguntas".

Ao lado do reconhecimento da importância dos docentes, muitos depoimentos ressaltavam pontos negativos. $\mathrm{O}$ aspecto mais recorrente dizia respeito à relação professor-aluno, quando ela era marcada pela falta de diálogo. Tais demandas quanto ao diálogo por parte desses jovens não se referiam apenas a ser alguém que conversa e faz brincadeiras com os alunos, mas dizia respeito ao modo de ensinar. Os jovens demandavam relações pedagógicas fundadas na valorização das dúvidas e da palavra do aluno em sala de aula. Os estudantes manifestavam, nesses depoimentos, o desejo de que a relação entre professor e aluno se baseasse na confiança mútua. Também desejavam um professor que não se pautasse apenas pela lógica transmissiva dos conteúdos.

Outros depoimentos frisavam a desmotivação dos professores, que se revelava no grande número de faltas durante o ano letivo. Os alunos 
associavam a baixa qualidade das aulas à falta de motivação dos docentes que não se preocupavam em preparar suas aulas, em usar outros recursos além da exposição oral e das anotações no quadro, ou que sequer respeitavam os horários.

Uma questão específica se referia à greve promovida pelos professores da rede estadual do Pará, em período um pouco anterior à realização da pesquisa. Os jovens se sentiam prejudicados, já que, além de "perder conteúdos", a qualidade das aulas tendia a cair depois do retorno dos professores. Sem deixar de reconhecer as dificuldades salariais e as piores condições de trabalho para os docentes, não havia uma reflexão junto aos alunos sobre essas questôes. Assim, os estudantes tendiam a exaltar o mérito individual do professor, calcado na sua "boa vontade", abnegação e esforço pessoal para se manter atualizado.

Como nos lembra Teixeira (2007, p. 426), "a condição docente se instaura e se realiza a partir da relação entre docente e discente, presente nos territórios da escola e da sala de aula, em especial". Através dessas falas, os jovens dão visibilidade aos problemas e dificuldades que tal relação encontra nos limites desses territórios. Há, nesse caso, uma consciência de que a desmotivação, muitas vezes vista como uma falta de compromisso com os seus alunos e com a escola pública, é produzida por desigualdades que se instalam no interior dos sistemas escolares e que afetam a profissão docente.

Esse tipo de depoimento poderia ser menos frequente se a escola se constituísse em um local de reflexão sobre a educação no país, seus impasses e desigualdades. Uma vez que o exercício da crítica não é um dos eixos que orienta o trabalho escolar e o desempenho no vestibular se apresenta como o objetivo último do ensino médio, os jovens tendem a idealizar o esforço pessoal dos alunos e dos professores e a centrar o foco de suas demandas nos conteúdos disciplinares e na qualidade das aulas.

\section{Os alunos também são responsáveis...}

O desinteresse e a falta de envolvimento com as atividades da escola não eram atributos somente dos professores. Os jovens reconheceram o desinteresse de parte dos alunos. Em muitos casos, eles revelaram que a escolarização assumia um sentido instrumental, voltado 
apenas para adquirir as credenciais exigidas para a inserção no trabalho. Os depoimentos reconheciam a difícil relação de muitos jovens com o ensino médio e buscavam várias explicações para isso: as condiçôes sociais e econômicas das famílias, o peso do trabalho, a falta de cobranças dos pais, entre outras. Para além de uma tendência a se autorresponsabilizarem pelo sucesso ou fracasso no percurso escolar, havia um reconhecimento comum de que a produção de si como aluno torna-se uma tarefa árdua e complexa. Tais dificuldades se refletem no percurso escolar de muitos jovens paraenses, marcado por atrasos e abandonos (Golgher \& Rezende, 2009).

\section{Aprendizagens: o que a escola deve ensinar?}

Com relação à percepção dos alunos sobre as experiências educativas desenvolvidas pelas escolas, havia o reconhecimento da importância de várias atividades realizadas na forma de projetos, oficinas, seminários, feiras de ciências, feiras culturais, entre outras. Tais atividades tinham o potencial de proporcionar aos jovens o acesso a informações ou a experiências de formação escolar e/ou profissional para além do currículo. No entanto, muitas vezes, a improvisação e a falta de condições básicas resultavam na não continuidade de iniciativas avaliadas como positivas por eles.

Muitos jovens tenderam a fazer a relação entre essas experiências e o desenvolvimento de habilidades gerais e competências básicas que são exigidas no mundo do trabalho, como falar em público e trabalhar em equipe. Em outros casos, a valorização dessas atividades referia-se ao fato de que elas ampliavam as oportunidades de preparação para o Exame Nacional do Ensino Médio (ENEM), vestibulares e/ou concursos públicos, além de divulgar informações sobre datas, inscrições e realização dos testes. Além disso, alguns eventos auxiliavam na escolha dos cursos para os quais iriam concorrer, atuando do ponto de vista da orientação vocacional.

Apesar do reconhecimento do papel positivo que desempenhavam na formação deles, os estudantes não deixaram de indicar a fragilidade que acompanhava a execução de muitas dessas experiências. $\mathrm{O}$ desenvolvimento de atividades que extrapolassem a sala de aula e a instituição acontecia de forma muito diferenciada entre as escolas. 
Muitos jovens reclamaram da inexistência desse tipo de ação em sua escola. Outras vezes, as atividades eram inconstantes, sem continuidade ou realizadas de uma forma precária.

O futuro profissional é uma das principais preocupações dos jovens brasileiros, como atestam algumas pesquisas (Abramo \& Branco, 2005), o que justifica o fato de muitos jovens demandarem a realização de projetos que proporcionem a eles melhores condições de inserção no mercado de trabalho ou de disputa por uma vaga na educação superior. Atividades nesse campo tendiam a ser valorizadas, na crença de que o acúmulo de experiências de formação profissional ampliaria as chances de uma inserção futura.

Associada à preocupação com o futuro profissional, havia uma crítica à qualidade e à forma como as aulas eram ministradas em suas escolas. Em algumas falas, acentuava-se o modo tradicional de lecionar de alguns professores, que não utilizavam outras abordagens para envolver os alunos. Em outras falas, transparecia uma preocupação com os conteúdos não abordados ou tratados de uma forma superficial, o que tinha impactos na preparação para os vestibulares.

Mesmo com a preocupação com os exames vestibulares e com a formação profissional, não se excluía o fato de que as escolas também deveriam preparar para a vida, de um modo geral. Não havia uma contraposição entre uma dimensão ou outra, mas a ideia de uma complementaridade entre a formação de habilidades específicas (saber se comunicar, dominar os conteúdos disciplinares etc.) e a formação geral.

Uma "aula mais atrativa" e "descontraída" para os jovens da pesquisa estava relacionada não apenas à metodologia do professor, mas ao fato de que deveria também tratar de temas de interesse deles. Ou seja, a crítica parecia dizer respeito não apenas às aulas em si, mas à ausência de propostas educacionais que, além dos conteúdos e habilidades disciplinares, dialogassem com as demandas juvenis em termos de orientaçôes, acesso a informaçôes, espaços de participação e diálogo, entre outros.

\section{Outras dimensões educativas da escola}

Embora pouco citada, a dimensão da sociabilidade emergiu em alguns depoimentos, especialmente naquelas escolas que desenvolviam projetos e incentivavam a participação dos alunos em atividades culturais 
e no grêmio estudantil. Os projetos articulados pelas escolas eram importantes para promover a interação dos jovens, o que contribuía para fortalecer os elos dos estudantes com elas. Tais experiências, no entanto, ainda eram esporádicas e distribuídas desigualmente entre as escolas. Em muitos casos, os jovens se queixaram das poucas oportunidades de lazer e de participação em atividades para além da sala de aula.

Os depoimentos chamavam a atenção para a importância da esfera da participação e da sociabilidade com relação aos aspectos subjetivos da relação dos jovens com a escola e suas autoimagens. A esfera da sociabilidade, potencializada por espaços de participação, permite desenvolver posturas, valores e aprendizados, além de fortalecer vínculos no plano das relações humanas e redes sociais que podem ter um impacto positivo na relação dos jovens com a escola. $\mathrm{O}$ fato de assumir posições de liderança, participar da organização de algumas atividades e tomar a iniciativa em algumas açôes desenvolve aspectos importantes no plano da autoconfiança e da identidade que podem contribuir para fortalecer os vínculos dos estudantes com o mundo escolar, como se constata em algumas pesquisas. Os espaços de participação como o grêmio estudantil também são importantes esferas de produção de valores e aprendizagens coletivas (Barbosa, 2007; Martins, 2010). No entanto, essas dimensões da sociabilidade e da participação tendem a ficar obscurecidas em muitos casos.

\section{Sintetizando...}

A escuta desses jovens nos permitiu constatar que a escola tem uma grande importância nas suas vidas, sendo uma instituição para a qual se dirigem muitas expectativas. Por outro lado, ela apresenta muitos limites e dificuldades na sua capacidade de responder ao que se espera dela.

Um aspecto mais visível se apresentou com relação às condições de funcionamento e infraestrutura. Algumas escolas funcionavam sem as condiçỗes básicas de higiene e conforto. Outras não tinham laboratórios e bibliotecas adequados. Em outros casos, embora houvesse esses equipamentos, as escolas não os usavam. Impressiona a diversidade de situaçóes entre as escolas de uma mesma rede de ensino que, 
a princípio, deveriam ter as mesmas condições de funcionamento. Mais gritante ainda é o fato de que tal desigualdade se manifeste ainda entre os turnos, com a permanência histórica de uma política de desvalorização do ensino noturno, fato comum no caso das escolas públicas do ensino médio no Brasil.

Nessa escola empobrecida, do ponto de vista da sua materialidade, também as relações humanas se fazem limitadas. Os professores e gestores foram alvo de muitas queixas por parte dos alunos. Embora reconhecendo e valorizando alguns que se destacavam em relação ao coletivo de profissionais da escola, constata-se uma grande desmotivação com relação ao fazer docente. Isso contribui para um clima escolar negativo, marcado pela desorganização e pela dificuldade dos jovens em se subjetivarem como alunos. Muitos depoimentos reconheceram a responsabilidade dos estudantes quanto a esse aspecto.

A pesquisa possibilitou descortinar um quadro de grandes dificuldades das escolas investigadas em dialogarem com seus jovens. Isso se torna grave no contexto de uma sociedade que passa por grandes mudanças, com novas exigências em termos de habilidades e conhecimentos. Numa sociedade onde a incerteza e a imprevisibilidade preponderam, ao mesmo tempo herdeira e reprodutora de desigualdades históricas, qual lugar a escola ocupará na vida deles?

Parece-nos que a escola não vem possibilitando uma formação humana mais ampla de seus jovens, de tal forma a contribuir para uma compreensão de si mesmos, das suas habilidades e desejos, bem como da realidade onde se inserem, com uma visão sobre o mundo do trabalho e suas demandas e exigências. No momento decisivo de escolhas de possíveis rumos de vida, parece que a escola pouco contribui para um conhecimento do que a universidade pode ou não oferecer, os cursos existentes com suas especificidades e demandas próprias. É muito sintomático que poucos deles se referiram, nos debates ocorridos, aos programas seriados de ingresso no ensino superior público no estado do Pará, como o Programa de Ingresso Seriado (PRISE), da Universidade do Estado do Pará, ou o Processe Seletivo Seriado (PSS), da Universidade Federal do Pará. Ou seja, os depoimentos parecem evidenciar que os jovens se encontram abandonados à sua sorte, a não ser pelo apoio da família. A escola e a sociedade em geral não lhes oferecem muitas perspectivas. Eles se encontram 
com limitados suportes institucionais, materiais e subjetivos que os ajudem a vislumbrar possíveis caminhos no seu futuro.

Acreditamos que a oferta do ensino médio deveria contemplar a diversidade de experiências juvenis que se expressou no encontro desses jovens em situação de diálogo. A partir de seus diferentes contextos sociais e histórias de vida, eles expressaram muitas demandas articuladas a partir de suas necessidades, gostos e estilos. Nesse sentido, apresenta-se à escola de ensino médio o desafio de se constituir em uma referência e uma oportunidade para que os estudantes das camadas populares tenham acesso a informações, habilidades e competências importantes para a sua formação humana e como cidadãos.

\section{Notas}

1. O projeto "Diálogos com o Ensino Médio" foi desenvolvido em 2009, no âmbito de uma cooperação técnica entre a Secretaria de Educação Básica, o Observatório Jovem da Universidade Federal Fluminense e o Observatório da Juventude da Universidade Federal de Minas Gerais. A proposta desenvolveu uma série de açôes que buscaram contribuir para favorecer a troca de informaçōes entre os atores envolvidos com o ensino médio brasileiro (estudantes, profissionais da escola, pesquisadores e gestores), ampliando o conhecimento sobre os jovens alunos desse nível de ensino. Para maiores detalhes, ver o relatório final nos sites <www.emdialogo.uff.br> e <www.fae.ufmg.br/objuventude>.

2. Segundo dados do Instituto Brasileiro de Geografia e Estatística (IBGE), entre 1995 e 2001, por exemplo, o número total de estudantes entre 15 e 24 anos passou de 11,7 para 16,2 milhōes. Nesse mesmo período, o ensino médio registrou um aumento de 3 milhões de matrículas, significando um crescimento relativo de 65,1\% (Sposito, 2005).

3. A Emenda Constitucional n. 59, de 11/11/2009, estabelece a obrigatoriedade e gratuidade da educação básica dos 4 aos 17 anos.

4. Uma análise mais aprofundada dessa questão encontra-se em Dayrell (2007).

5. Nos limites deste texto, não nos detemos à análise de dados da pesquisa de cunho quantitativo. Em função da impossibilidade de realização de uma ampla pesquisa com os recursos disponíveis, optou-se pela utilização de bases de dados secundárias. Uma análise mais ampla desses dados pode ser encontrada no texto "Um olhar sobre o jovem e o Ensino Médio no Pará”, de André Braz Golgher (CedePLAR/UfmG) e Daniela Rezende (DCs/ufv). Disponível em: <www.fae.ufmg.br/objuventude>.

6. Uma descrição detalhada da metodologia pode ser encontrada no relatório final da pesquisa disponível nos sites: <www.emdialogo.uff.br> e <www.fae.ufmg.br/objuventude>.

7. A linha de pesquisa denominada Escola Eficaz reúne estudos emergentes a partir dos anos de 1970 que pretendem abrir a caixa-preta da escola para "compreender e conhecer, em cada contexto social, as várias características da escola que podem interferir no desempenho dos alunos" (Soares, 2002, p. 8). 


\section{Referências}

ABRAMO, H.W.; BRANCO, P.P.M. (Org.). Retratos da juventude brasileira: análises de uma pesquisa nacional. São Paulo: Instituto Cidadania; Fundação Perseu Abramo, 2005.

BARBOSA, D.S. "Tamo junto e misturado": um estudo sobre a sociabilidade de jovens alunos em uma escola pública. 2007. Dissertação (Mestrado em Educação) - Faculdade de Educação, Universidade Federal de Minas Gerais, Belo Horizonte.

BOURDIEU, P.; PASSERON, J.C. Los herederos: los estudiantes e la cultura. Buenos Aires: Siglo XXI, 2003.

CANÁRIO, R. O que é a escola?: um olhar sociológico. Porto: Porto, 2005.

CASTRO, J.A.; AQUINO, L.M.; ANDRADE, C.C. (Org.). Juventude e politicas sociais no Brasil. Brasília, DF: IPEA, 2009.

CORTI, A.P.; SOUZA, R. Que ensino médio queremos?: pesquisa quantitativa e grupos de diálogo sobre o ensino médio. São Paulo: Ação Educativa, 2009. (Relatório final).

DAYRELL, J.T. A escola faz juventudes?: reflexōes em torno da socialização juvenil. Educação \& Sociedade, Campinas, v. 28, n. 100, p. 1105-1128, out. 2007.

DAYRELL, J.T. et al. Juventude e escola. In: Sposito, M.P. O estado da arte sobre juventude na pós-graduação brasileira: Educação, Ciências Sociais e Serviço Social (1999-2006). Belo Horizonte: Argumentum, 2009.

GADOTTI, M. Diversidade cultural e educação para todos. Rio de janeiro: Graal, 1992.

GOLGHER, A.B.; REZENDE, D. Um olhar sobre o jovem e o ensino médio no Pará. Belo Horizonte, 2009. (Mimeo.).

KRAWCZYK, N. O ensino médio no Brasil. São Paulo: Ação Educativa, 2009. 77p. (Em questão, 6) 
MARTINS, F.A.S. A voz do estudante na educação pública: um estudo sobre a participação de jovens através de grêmio estudantil. 2010. Dissertação (Mestrado em Educação) - Faculdade de Educação, Universidade Federal de Minas Gerais, Belo Horizonte.

PINTO, J.M.R. O valor investido garante qualidade? Desafios da Conjuntura: o ensino médio no debate educacional, São Paulo, n. 26, p. 10-11, out. 2008 .

SOARES, J.F.; ALVES, M.T.G.; MARI, F.A.O.T. Escola eficaz: um estudo de caso em três escolas da rede pública de ensino do estado de Minas Gerais. Belo Horizonte: Grupo de Avaliação e Medidas Educacionais (GAME); Faculdade de Educação/UfmG, 2002. 114p. (Relatório de pesquisa).

SOARES, J.F; BROOKE, N. Pesquisa em eficácia na escola: origem e trajetórias. Belo Horizonte: UFMG, 2008.

SPOSITO, M.P. Algumas reflexões e muitas indagações sobre as relações entre juventude e escola no Brasil. ABramo, H.W.; Branco, P.P.M. Retratos da juventude brasileira: análises de uma pesquisa nacional. São Paulo: Instituto Cidadania; Fundação Perseu Abramo, 2005. p. $87-128$.

SPOSITO, M.P.; GALVÃO, I. A experiência e as percepções de jovens na vida escolar na encruzilhada das aprendizagens: o conhecimento, a indisciplina, a violência. Perspectiva, Florianópolis, v. 22, n. 2, p. 345-380, jul./dez. 2004.

TEIXEIRA, I. Da condição docente: primeiras aproximações teóricas. Educação \& Sociedade, Campinas, v. 28, n. 99, p. 426-443, maio/ago. 2007.

Recebido em 24 de março de 2011.

Aprovado em 28 de abril de 2011. 